\title{
A FEBRE SELVAGEM \\ ou \\ ELEUTÉRIA \\ ou \\ O TRIDENTE DA ESPERANÇA
}

\section{Rauer}

\section{Rauer.rauer@uol.com.br}

O Nogueira, de Machado de Assis, teve certa vez uma conversação, contava ele dezessete anos à época, que jamais pôde entender. Pois acabo de assistir a um diálogo, tenho eu vinte e cinco anos, cujas magia e verdade, se é que as apreendo, me enojam, fascinam, angustiam.

Apaixonado por histórias de família, visito aos domingos o meu tio João Rosa, que me desfia suas lembranças. Hoje encontrei-o com um amigo, Sauber Queirós. Meu tio insistiu para que eu ficasse:

— Junte-se aos maus e torne-se um deles, Júnior.

— Não quero atrapalhar.

— Bobagem. Senta aí.

— Estamos praticando o principal divertimento dos aposentados.

- E qual é? 
- Falar mal da vida alheia.

- Iniciei-me agora nesse esporte, com o tio.

— Isso é um menino de ouro, professor de filosofia.

— Seu tio tem coração mole, não bota maldade.

A risada de meu tio evoluiu baixa e rouca, depois explodiu breve e seca no ar.

— Uma pimenta faz bem - Queirós completou.

Deixaram-me à vontade. Era um reencontro de velhos camaradas. Queirós saíra de Noroeste há mais de quinze anos, em mil novecentos e oitenta e três. Ele disse se lembrar bem da data, mas queixou-se de que sua memória o traía nas coisas mais recentes. Tio Rosa o elogiou: ele estava firme como uma aroeira, parecia rejuvenescido, e apresentava as suas opiniões com a franqueza habitual. Busquei café, esvaziei o cinzeiro. Abri uma latinha de cerveja, nenhum dos dois me acompanhou.

- Parece que vai cair um temporal - tio Rosa disse.

Queirós observou que há muitos anos não via uma enchente. Tio Rosa garantiu que a última foi em mil novecentos e cinqüenta e oito, há quarenta anos. Falaram de prejuízos, mortes, desaparecimentos. Lembraram-se de saques no comércio, do isolamento com a queda da ponte de acesso à cidade, dos espertalhões tirando vantagem da tragédia. Tio Rosa confidenciou que durante a enchente teve início o grande amor da sua vida.

- Foi também nessa época que desenvolvi o meu hobbie predileto, a fotografia - disse tio Rosa.

Abri outra latinha de cerveja. 
— Esse menino saiu a quem?

- Como assim?

— Uai, parece um pé de cana.

— É filho do Joca.

— Cadê o Joca?

— Teve um problema na próstata, mas se recupera bem.

- Papai anda deprimido. Sonha com a mamãe, desata a chorar.

— Minha cunhada — tio Rosa fez um ar consternado, — há três anos...

- Já era para seu pai ter superado. Ele é bem mais novo que eu, mas íamos juntos às ganças, jerebar. Dos irmãos, era o mais mulherengo, não era?

- Sempre foi.

- Papai até arrumou umas quengas. Depois veio a depressão, a diabetes, a próstata...

Queirós perguntou por tio Juca. Tio Juca era fazendeiro, mas perdera metade de suas terras para um banco e a outra metade num aval à amante. Restava-lhe pequeno sítio, meia dúzia de vacas e algumas galinhas. Tornara-se eremita, misantropo, misógino.

Urinei no quintal, ao pé de uma goiabeira. Na varanda, tio João Rosa abria os braços e Queirós, enquanto falava, batia no tampo da mesa com o indicador. Por trás da casa subiam nuvens cor de chumbo, carregadas. Ressabiada com os trovões, Baleia, a vira-lata de meu tio, aninhara-se no tapete à porta da cozinha.

Calor. Tarde abafada. Peguei mais uma cerveja, o saleiro e o paliteiro. Levei um queijo Minas e piquei uma porção de charque. Tio João Rosa formara-se em 
línguas e em literatura e amava as tradições sertanejas. Seu amigo fora corretor de gado e atualmente comerciava imóveis. Tio Rosa envelhecera digno como um buriti remanescente num campo que fora, outrora, uma várzea fértil. Queirós falava:

- O mundo gira, gira, mas não muda.

Meu tio, mastigando queijo, resmungou algo em concordância.

— Às vezes me pergunto se compensa ser honesto.

— Tudo é culpa desses juros malucos...

— Um dia ainda saio dinamitando os bancos. Em oitenta e dois anos de vida nunca vi tanta roubalheira como agora.

- Os milicos de sessenta e quatro levaram muito mais, tudo em surdina, sob censura geral.

— Nos tempos do Getúlio foi pior.

— Que nada!

- Roubava, batia...

— Mas o país cresceu. Os milicos deixaram recessão, inflação...

— Seguramente, agora está pior.

- Uma crise eterna, a do nosso país.

- Fico pensando... Trabalhei a vida inteira, agora "camelo" para uma multinacional; estou em Noroeste para comprar a casa que foi do Goulart velho... E nessa idade, se não pegar no batente, passo fome...

- Os Goulart quebraram mesmo?

— Dinheiro que veio fácil... 
— Fácil?!

— De forma desonesta.

— Como foi? - perguntei.

- A origem de tudo foi com o sogro do Goulart. O velho tinha só um olho mas enxergava como ninguém. No dia em que o mataram, ele matou três. Gente ruim tava ali.

— Ouvi dizer que os Oliveira também estão balançando.

- Os bancos, Rosa, tudo fica para os bancos.

- Além disso, a fortuna deles é meio obscura...

- Aqui em Noroeste não tem nenhuma conta bancária sem sangue.

- A dos Ayala?

- Negativo.

Queirós balançava a cabeça, parecia dar uma reposta positiva.

- Cunha?

— De jeito nenhum.

— Rodrigues, Netan?

— Todas com falcatruas, roubos, assassinatos. Todas com um cadáver no armário.

— Sei de uma limpa, Sauber.

— Você está com cinqüenta e...

— Cinqüenta e nove no mês que vem.

- Mas continua inocente, Rosa. Igual menino. 
Queirós acendeu um cigarro e completou:

— A única coisa limpa aqui é o lençol do Mata Hari...

— Como assim? Não entendi.

- A cama do Mata Hari é mais limpa do que a ficha de qualquer um da elite dessa cidade.

— Sei de uma família limpa.

- Qualquer que seja, garanto que você não sabe da missa, nem a primeira conta do rosário.

Meu tio suspirou.

— Nunca ouvi nada sobre os Pagliuca.

Queirós riu. Seu olhar tinha um brilho safado.

- Que acabaram de pegar o Carlitinho numa pose, por assim dizer...

— Isso é maledicência da oposição.

- Mas a história correu meio mundo - eu disse.

- Meio mundo... A bem dizer, pegaram ele com a boca na massa...

- Fofoca pura.

— Essa degeneração... Essa depravação... Queirós ficou pensativo; depois, concluiu: — tem raiz secular essa perversão.

Ficamos em silêncio. Virei o restinho da cerveja. Tio João Rosa suspirou fundo. Queirós tinha uma expressão velhaca. Perguntei a ele porque dizia que a corrupção moral dos Pagliuca tinha raiz secular. Ele iniciou uma dessas saborosas histórias antigas que sempre me empolgaram.

— Antes, ele disse, no fim dos anos dez, mais ou menos à época em que o http://www.fclar.unesp.br/grupos/casa/CASA-home.html 
Pagliuca nasceu, teve um golpe... coisa de máfia italiana, de cinematógrafo.

- Coisa de cinema, Sauber.

— E o Carlitinho com uma bicha, na prefeitura, é coisa de cinema pornô.

— Deixa de ser nazista.

— Eu não sou nazista!

— Você, sim senhor.

- Ora, Rosa.

— Queirós, você está é com inveja do sucesso do Carlitinho.

- Eu? $\ldots$

— Sim, senhor.

— Mas eu não chupei a pica do Mata Hari em plena prefeitura...

— Sauber, essa história é intriga.

— Não é não, senhor Rosa. Não é não.

— O Carlitinho não leva tipo...

- Acho que leva, eu disse.

— É um homem alto, atlético, boa pinta...

- Isso é verdade, Rosa. Ele não saiu com aquele tipinho atarracado do Pagliuca, tem um porte assim como o seu.

— Ele se parece com a nossa família, inclusive na solteirice convicta.

— Pode também... ter saído à mãe...

- Como?

— Você conhece a história da mãe dele? 
$-\operatorname{Sim}$.

- Claro que conhece, dona Eleutéria era sua tia.

- Sim.

— Um exemplo de esposa. Fiel, dedicada, religiosa.

- Uma mulher e tanto.

— Agüentou a vida inteira um marido a quem não amava.

$-\operatorname{Sim}$.

Queirós sentou-se na ponta da cadeira, curvando-se para a frente:

- Morre aqui a nossa conversa?

- Como assim?

— Tudo que falarmos, morre aqui?

- Acha-me com cara de fofoqueiro?

- Me garante?

- Palavra de homem.

— Não duvido. Mas o que for ventilado aqui, morre aqui?

- Com certeza.

— Se me perguntarem, eu desminto. Combinado?

— Nesse armário tem quantos cadáveres?

— Tem um cemitério inteiro, menino. Queirós agitou as mãos e juntou os dedos, como a aumentar com o gesto os corpos no cemitério.

— Serei um túmulo, tio Rosa assegurou.

Queirós fechou os olhos e recostou-se no espaldar da cadeira. Respirou a alma. 
Pareceu mergulhar em agradáveis lembranças.

— Vou confiar em você, hem... disse lentamente.

— Serei um túmulo, tio Rosa repetiu.

- Pois saiba que Eleutéria Rosa Pagliuca teve um amante.

— Sem essa, meu tio engasgou.

— Conheço pessoalmente. Sei da história...

— Tá delirando...

— Foram vinte e dois anos, dos vinte e sete que viveu casada.

— Isso é palhaçada.

— Conheço a história toda por dentro.

— Duvido que saiba de algo.

- Estou te contando... Eleutéria. Queirós trinchou um pedaço de charque com o dente, - ela aprontava.

— Deixa de papo.

— Eu até acho que você desconfiava de alguma coisa...

— Júnior, não dê bola, ele não sabe o que está falando.

— Sei e asseguro: Eleutéria teve um amante até a morte.

- Impossível, sem chance...

— Eleutéria... não era a santa que você propaga...

— Seu pai trabalhou como guarda-livros para o Pagliuca velho, mas daí a...

- Meu pai me contou alguns podres da chegada deles a Noroeste, mas o que sei é do meu tempo, do nosso tempo. Queirós frisou a palavra "nosso". 
— Sim, você ficou amigo da família, até meio rival do... do... pai do Carlitinho...

— Eu me atrasara nos estudos, fizemos o clássico juntos.

- Lembro de um programa de rádio, eu devia ter dez anos, vocês duelando em forma de poesia.

- Veleidades. Na literatura, ele era melhor. Tinha conhecimentos do modernismo, até do concretismo. Eu era parnasiano na forma, romântico na alma. Uma besta, eu era.

— Mas o público pendia por você.

- Aplauso ignaro!

— Vocês eram muito amigos?

— Na boemia e na farra.

- Eh, Júnior, ficou famoso na cidade o vira-vira de pinga que disputaram. Nenhum arrepiou pé, até os dois desmaiarem.

— E na literatura, como era o "duelo"?

- Maravilha... Queirós se emocionara... são lembranças de um tempo muito especial...

— Vocês eram repentistas?

— Éramos, Júnior. Nós dois, as violas, e o público vibrando. O que ninguém sabia, menino, é que nós dois cantávamos inspirados por Eleutéria, sonhando com o amor de Eleutéria.

- A rivalidade então era grande.

- Nossa rivalidade não era literária, era bem outra... 
Queirós interrompeu a frase, ficou olhando o nada. Um trovão sacudiu a casa. Baleia, assustada, ganiu fininho. A chuva caiu em gotas grossas, pesadas. Queirós deixou escorrer as palavras cuidadosamente:

— Eleutéria era para ser minha, não dele...

Tio Rosa parou o gesto, a boca aberta. Devolveu o queijo ao prato. Passou a mão pelo braço e puxou a manga da camisa para cima. Primeiro a esquerda, depois a direita. Queirós atirou longe o toco do cigarro, virou um restinho de café da xícara, aceitou a latinha de cerveja que eu acabara de abrir. Havia eletricidade nos olhares.

— Devo entender... tio Rosa hesitou. Depois, num arranco, devo entender o quê?

— Eleutéria e o Pagliuca...

- Sauber!

— Você a tomou dele? eu perguntei.

- Foi uma disputa insana...

- Sauber! $\ldots$

— Mas... como não apaixonar por uma mulher igual Eleutéria?

- Sauber...

— Raios! Me chame pelo meu velho e honrado sobrenome português.

— Onde sua mãe arrumou esse Sauber, alemão?

— Invenções. Queirós é melhor.

— E a tia Eleutéria? eu era um poço de curiosidade. 
— Requestou um amásio fixo durante vinte e dois anos...

— Que bobagem!

- Sei datas, nomes.

— Fofocas, tudo fofocas.

— Desde 1961, no aniversário de um ano do Carlitinho...

- Você está... está...

— Está o quê?

— Inventando, jogando verde, falando a esmo para tirar informações.

— Sei de tudo, Rosa. Vivi a situação toda e sei que Eleutéria...

— Sauber... Queirós...

- O que foi, Rosa?

— Você não vai tocar nesse assunto, não vai falar dessas coisas de família para o meu sobrinho.

— Ora, ora, ele é um filósofo, sabe que a carne é movida a desejo e paixão.

Eu estava atordoado com o passado redivivo à minha frente. Como um adolescente ingênuo que se gaba nas proezas dos amigos, indaguei:

- Você ficava com a tia Eleutéria?

— Quê que você acha, menino?

— Não, meu tio tampou o rosto, não fale nada!

— Que importância tem isso agora?...

— Não fale nada, Queirós...

— Não estou te entendendo. 
Tio João Rosa fez um gesto lento com a mão. Respirou fundo. Os dois olhavam-se: que revelações surgiriam?

— É um delírio... tartamudeou titio.

— Foram, eu sei bem, foram vinte e dois anos...

Queirós estava de cabeça baixa, o olhar de tio Rosa perdia-se no infinito.

- Vinte e dois anos... eu, ela...

- Você...

- Eu... Nós...

-...Vocề!?...

- Claro.

- Você?

— Sim, eu... nós...

— Você?!

— Nós. Eu e ela.

— Você, um solteirão?

-É.

— Um solteirão convicto?

- Sim.

— Um solteirão inveterado...

—É o que todos pensavam.

— Você está dizendo que... vocês... 
— Nós dois.

— Vocês dois?

- Era como um...

- Diga.

- ...um... casamento.

— Essa concupiscência imunda?

— Nós nos amávamos.

— Sim, amavam?... Amancebaram-se, isso sim.

- Eu me sentia comprometido, Rosa. Fiquei esperando ela terminar o casamento. Como sofri! Só minha mãe soube. Nem ao meu pai eu contei.

— E ela? — eu perguntei.

— Minha mãe?

— Tia Eleutéria, sua mãe, como agiam, o que achavam da...

- Minha mãe me dava força. A presença dela ao meu lado era de apoio e compreensão. Mesmo definhando com a doença, minha Eleutéria morreu em silêncio.

— Numa situação assim o melhor é todos serem discretos.

— Discretíssimos.

— Nunca ninguém desconfiou?

- Jamais.

- O Pagliuca, pai do Carlitinho?

- Com aquela cara de buldogue velho, mongolóide, ele queria era cuidar de 


\section{(c)

seus bois, ler em paz os seus livros. Menino, ele a amava sem peias, mas era grosseiro, inábil. Ele a usava sexualmente, machucava-a, e ela se submetia.

— Nunca ninguém desconfiou de nada?

— Ninguém.

— Foi difícil, eu sei, foi difícil, tio Rosa comentou.

- Como?

— Deve ter sido muito difícil.

— Foi doloroso. Acostumamos. Aí a minha Eleutéria morreu e eu me mudei. Viver aqui perdera o sentido para mim.

A chuva transformara-se em temporal, felizmente no sentido em que não invadia a varanda. Queirós acendeu um cigarro. Tio João Rosa pegou a garrafa térmica, serviu-se de café. Suas mãos tremiam.

— E o Carlitinho?... perguntei ao Queirós.

- O que tem ele?

- A história dele na prefeitura.

— Simples: mantém o seu caso com o Mata Hari, mesmo tendo ingressado na política.

Queirós tragou, tossiu, cuspiu. Meu tio, nervosamente, coçava o cocoruto, onde os cabelos raleavam. Aceitou a cerveja que ofereci a ele. Queirós continuou:

— O Mata Hari sente pelo Carlitinho algo meio maternal.

- Devo entender que o Carlitinho chupa no Mata Hari como no seio materno? eu brinquei.

Tio Rosa grunhiu. 
— É piada mas é a verdade. Queirós caiu na risada.

— Um prefeito pego numa situação dessas...

— Prefeito, presidente da República, rei, todo mundo continua gente.

—É verdade, Rosa, continua. Continua sendo gente e sendo animal.

— Ah, a febre selvagem da paixão... eu disse.

— Júnior... Eu lutei contra os meus instintos, mas é porteira que não se tranca - Queirós suspirou. Eu amava de verdade a minha Eleutéria.

— Parece mais uma idealização platônica.

— Não, meu filósofo, não era nem platônico nem etéreo. Éramos carne viva, pulsante. Eleutéria era uma fêmea inigualável!

Percebi tio Rosa fechar o semblante, mudei de assunto:

— Queria saber como se fez a fortuna dos Pagliuca.

— Meu pai me contou. A casa que herdei foi o preço do silêncio dele.

- Como assim?

- Veio um baú de dinheiro falso no meio das encomendas para a loja do velho Pagliuca. Acho que impresso na Itália, pela Máfia. Era um bazar, vendia de tudo: sabão, roupa, secos e molhados. Tinha até bíblias. Um empório apinhado de mercadoria. Meu pai levou mais de dois anos para diluir as notas falsas no movimento da loja. Depois o comendador a vendeu, comprou uma fazenda, e adiós, problems.

— Então não se salva ninguém?

- Como assim?

— Não se salva nenhuma fortuna sem sangue? 
— Salvamos eu, pobretão, e o lençol do Mata Hari.

— Você é um hipócrita, você é que não se salva!

- Rosa!

— Não consigo acreditar... você e Eleutéria... Você é um falso, cínico!

— Quê que é isso, agressão, é?

— Uma mulher imaculada, sofrida, você a seduzindo...

- Pára, Rosa. Já acabou, não existe mais. Ela não tinha nada de pura. Era uma depravada. O mínimo que ela dizia é que a única coisa boa do casamento é o adultério. Adorava sexo, por cima, por baixo, de lado, com a boca, na frente, atrás. Ela, de qualquer jeito, urrava de prazer.

— Isso é que não!

- Sim. Amamos, gozamos. Fui feliz e infeliz. Ela prometia o Paraíso para além da medíocre vida que naquele momento nos era possível, mas deu-me o Inferno e deixou-me a saudade.

— Por quê o Inferno?

- Porque, meu jovem, ela adorava garotinhos, vitalidade, variedade... Ela caçava os filhos dos agregados na fazenda, espojava-se com qualquer um. É isso, Rosa: ela transava com todos os rapazinhos da fazenda. Era a sua diversão, a sua vingança ao marido. Mas amar, ah, ela amava era a mim.

- Não!...

— Rosa, meu amigo, melhor salvarmos a nós que ficamos.

— Será que eu tenho alguma salvação?

Queirós jogou longe o toco do cigarro, balançou a cabeça: 
- Jamais.

- Por quê?

- Herança genética.

— Como assim?

O sorriso irônico anunciou a maldade:

- Burrice acumulada. De um avô fazendeiro você tá aí, na pindaíba, não consegue sequer uma pensão por invalidez.

— Tenho sido um trouxa na vida, eu sei.

— Trouxa maior foi o seu avô.

— Sempre ouvi elogios a ele, eu disse.

- Menino, veja se não concorda comigo: vender terras pra viver na cidade emprestando dinheiro a juro não é coisa de idiota?

— Formou os seis filhos, atalhou tio Rosa.

— Não vejo graça.

- Bem, agiotar é uma sacanagem institucionalizada, uma das podridões do país.

— Mas o otário do seu bisavô, menino, administrou mal, faliu, quebrou.

- O mundo precisa de uma nova ética econômica, pontificou tio Rosa, parecendo feliz em ver a conversa mudar de rumo.

— A roubalheira bancária tem que acabar, aduziu Queirós.

- O capitalismo precisa de princípios que, aliás, nunca teve, de ética e de justiça, completou tio Rosa. 
— Não o sabia adepto da terceira via...

- Nem terceira nem sétima vias, Queirós. Eu não quero via nenhuma. Ou antes, quero todas, antropofagicamente. E elejo o barroco como o discurso do nosso apocalipse.

— Isso é uma via, eu brinquei, ou é um trevo, ou um cebolão?

—É uma piada, menino, como de resto...

Tio Rosa fez um gesto, pareceu abarcar o mundo em suas mãos.

- Vejam: aqui, miséria crescente; noutros modelos econômicos, totalitarismo. Uma terceira via, filha bastarda desses regimes, seria um frankenstein, um drag queen, uma aberração na natureza das coisas...

Queirós e eu olhávamos fixamente para tio Rosa.

- Mas afinal, ele prosseguiu, não é o natural, nesse nosso mundo, uma aberração? O que é uma aberração? Tudo... e nada!

Abri duas latinhas de cerveja e servi três copos.

— Meu bisavô, ele foi honesto? perguntei.

— Sim, foi - tio Rosa respondeu de bate-pronto.

— Honesto e burro. Queirós limpou o bigode com as costas da mão.

— Burros fomos nós - a voz de tio Rosa soou mais alto do que o normal. Nós dois, burros, cornos. Eu pensar que era esperto, vá lá, eu ainda era imberbe... Mas você... Saber e aceitar os rapazolas... eu nunca soube de nada... Eu não aceitaria...

— Seja explícito, a voz de Queirós também alteou.

- A Eleutéria, a minha Eleutéria... A minha Eleutéria, desgraçado, a mim é 
que ela amava. Eu a tinha, aquele suave amor era meu... aquele amor de casta entrega era todo meu, somente meu...

- Rosa!

- Pensar que eu a dividi...

- Por isso é que ela me queria só um dia na semana. A mão de Queirós parecia tremer quando levou o copo de cerveja à boca.

Tio Rosa segurava a cabeça com as duas mãos, os cotovelos fincados na mesa.

— A mim também! a voz de tio Rosa era um lamento.

No silêncio angustiante, meu espírito detetivesco me traiu:

— Tia Eleutéria tinha um comborço para cada dia da semana?

A dúvida inoportuna ficou sem resposta. Os dois se entreolharam, cabisbaixos. Pelo sofrimento dos dois, pela minha indagação cretina, pelo destino que, naquele momento, condensara aquelas duas vidas, ali, à minha frente, eu me queria um avestruz, a cabeça bem funda no fundo do infinito.

Enquanto isso, a chuva caía tempestuosa na tarde negra.

Eu pensava naquela situação absurda, que poderia ter sido trágica, que agora soava até meio cômica, mas que era uma descoberta inesperada no crepúsculo daquelas vidas. Que raciocínio ético, que consideração humana fazer nessa hora? Os dois olhavam a chuva, sabe-se lá que sentimentos abrigando no peito.

Tio João Rosa talvez se lembrasse da saga inglória de Fabiano fugindo do sertão, o livro que mais amava de seu autor preferido, ou quem sabe da Luíza, de Caetés, inspirada em heroínas como Bovary, como Karênina, ou como a Luísa do Eça.

A tempestade sacudia as árvores. Como seria melhor se Queirós fosse embora. http://www.fclar.unesp.br/grupos/casa/CASA-home.html 
— Viver é perigoso, disse tio Rosa.

Esfriava. Fui ao armário, peguei uma garrafa de pinga e três copinhos.

— Desce bem... tio Rosa disse, desce bem... Esfregou as mãos - numa hora dessas uma branquinha... A voz de tio Rosa embargou.

A pinga desceu muito bem.

Continuamos ali, emudecidos, solitários, solidários, cada um imerso em si mesmo, cada um preocupado com o que o outro estivesse pensando.

O vento sacudia as árvores.

Tio Rosa se levantou e caminhou lentamente para o interior da casa. Percebi que remexia, às escuras, em seu velho guarda-roupas. Voltou com uma caixa amarelada pelo tempo, sentou-se, suspirou. Empurrou a caixa sobre a mesa e murmurou, sofrido: "vejam".

Eram fotos, dezenas: tia Eleutéria em paisagens bucólicas, em poses glamourosas, em trajes íntimos; noutras, ela nua, nuazinha, nua em pelo. Tio Rosa mostrou-me numa foto, eu, meninote, acolhido carinhosamente por Tia Eleutéria à morte, em seu leito, ela muito magra, mas ainda linda e eu, alumbrado, me lembrei de como ela era fascinante. Aqui ou ali, o Queirós, o Pagliuca. Tio Rosa, adolescente, em uma formatura escolar: ao seu lado, a sua paixão recôndita... Carlitinho montado num cavalo de pau, a casa na fazenda, os rapazes... carvoeiros, catadores de algodão, pequenos vaqueiros, rostos tristes onde surgia a sombra do bigode... E Eleutéria enigmática... vaporosa... fascinante... o olhar lascivo profundo, magnético, acorrentando-me.

Queirós, trêmulo, olhava as fotos. Os galhos das árvores chacoalhavam.

Baleia refugiara-se no interior da cozinha. A cada trovão mais forte ela gania 
susto e medo. Perguntei se conheciam a história de Cérbero, o guardião dos infernos, o mastim hediondo que se apresenta com muitas faces, a ambígua presença que protege e intimida.

No silêncio pesado que se fizera, no crepúsculo que avançava, as faces de Cérbero ocupavam o meu pensamento. Não sei se da bebida ou se realmente, mas as muitas cabeças de Cérbero transformavam-se, fundiam-se, desdobravam-se, e a ambivalência das suas faces me desafiava. Pareciam dizer-me, as carrancas do Cão do Hades: a dicotomia do certo e do errado está sepultada, há de existir uma moral nova que faça a felicidade das pessoas, que transforme o bem e o mal num tridente além da virtude e do infortúnio.

As faces de Cérbero se revezavam com a aparência do Pagliuca, do Queirós, do tio João Rosa... Tia Eleutéria casada com um coronel velhusco... amante de tio Rosa, um menino alto e magro, quixotesco, mais novo que ela... barregã do Queirós, tronchudo, baixote, pragmático, medíocre, muito mais velho que ela, mais velho até que o Pagliuca com quem se casara e que já era um velho para ela...

Tio Rosa começou a falar de tia Eleutéria. Disse que era linda. Ela era muito clara, perfil longilíneo, tinha sardas no colo do peito e sorria com dentes brancos e iguais como ele nunca encontrou em outra mulher. Era uma pessoa extraordinária, dedicava-se às obras sociais da paróquia, suportava estoicamente um marido intragável.

— Ela me dizia que você tinha uma queda por ela, nunca supus...

— Eu era apaixonado, Queirós, apaixonado.

O sentido da chuva mudara e a água invadia a varanda. Afastamo-nos um pouco.

As fotos mostravam aquela mulher linda e suas muitas faces, seus incontáveis http://www.fclar.unesp.br/grupos/casa/CASA-home.html 
camaradas, seu leito enciclopédico...

Cérbero se multiplicava em dezenas de concubinos anônimos para todos os dias da semana, para todos os dias de uma vida, preenchendo multissêmicas expectativas nos sonhos da mulher insaciável, uma variedade excêntrica de gostos, inexplicável, que subsistiu até tia Eleutéria ser corroída pelo câncer aos cinqüenta anos.

Coloquei as mãos nos bolsos, para fugirem do frio, e acariciei a intumescência copuladora. Mas a cabeça continuou longe, muito longe, mergulhada naquele passado de falcatruas e golpes bancários, naquelas fortunas regadas a sangue onde está o tridente do meu Cérbero? - e nos amores, múltiplos amores - onde o tridente, Deus meu, onde? - ambíguos arrebatamentos que se perdiam no momento em que se realizavam, amantilhos furtivos, multiinfinitos, idealizados, amor e ciúme enlouquecendo os namorados, Cérbero esmigalhando homens e rapazolas aos seus pés, todos deliciando-se no mesmo leito, nos lençóis limpos em que agora me imagino, mergulhado nos braços calientes e no marmóreo amplexo de tia Eleutéria, imerso na angústia do diálogo a que assistia, na agonia que liquefez o imutável, na dor onde ilusões foram perdidas, onde vivenciei paixões revivescidas, onde já antevejo o crepúsculo da minha vida, onde vou, sim, onde vou me perder no magma da terra, onanista, idsélfico, quiromaníaco, submerso ah, esperança que me corrói, desespero que me consome! enfronhado, túmida explosão, nos sortilégios lúbricos de Eleutéria, a borboleta venérea, a epifania noturna, a esfinge sedutora.

Tio Rosa batia com os punhos no tampo da mesa:

- Minha Eleutéria não era uma degenerada, uma depravada... A minha Eleutéria era sensível, cheia de remorsos... Eu a chamava de minha pura paixão 
perfeita...

Um raio iluminou a varanda. Parecíamos fantasmas de um tempo ancestral. Eu via Eleutéria entre as sombras, a indecifrável Eleutéria, submissa ao marido, pudica com o sobrinho, devassa com o Queirós, sôfrega com os seus garotos, e, no meu leito, amante apaixonada, febril, selvagem. A tronga e o discípulo de Onã (mantenho o olhar fixo na foto de Eleutéria deitada de lado, a mão estendida a convidar, o sorriso cativante, o sedutor contorno das nádegas...) livram do Inferno a espécie, fazem o elogio fúnebre da esterilidade, conduzem os mortos da platéia para além da inútil procriação insana. O bem, o mal e a verdade fundem-se e confundem-se e separam-se mesclados no enigma do amor, da paixão e da morte que a tudo encerra. Como no Sinai, uma voz de fogo cala dentro de mim, Javé fala a Moisés, grava na pedra:

- As muitas genoprosopoedras de Eleutéria finalizam em máscara mortuária, imolam-se a Moloc, tornam-se ré de morte. Porque, em verdade vos digo, a esperteza é pó e ao pó voltará, o prazer anunciado vingará como inexistência e a esperança de finitude defrontar-se-á com a eternidade, a aliança morrerá forjando-se como liberdade, as ilusões fenecerão em flor que nunca se abre.

Um trovão, imenso, ricocheteou nas trevas, fez a casa tremer. Éramos um quadro em chiaroscuro, morto o inapreensível triálogo, quiçá heptálogo.

Servi nova rodada de pinga. Nós três viramos os copinhos de uma vez. A voz de tio Rosa, viscosa, impregnou o silêncio:

- Ela foi o meu devaneio adolescente... A minha única mulher, a minha ineludível amiga, a minha vida... 
Um ronco agônico, um lamento que se cortava a si mesmo rompeu do peito de tio Rosa. Arfou:

— Era a minha prisão, a minha liberdade... A mãe do meu Carlitinho...

Queirós e eu nos entreolhamos. Tio Rosa levou as mãos aos olhos. Pareceu soluçar. Queirós se levantou e apanhou a bengala. Ia tocar os ombros de tio Rosa, mas colocou o chapéu e, sem falar palavra, desapareceu na tempestade. 